\title{
Prediction of supply and demand for jobs in the Czech Republic
}

\author{
Veronika Machováa $^{*}$, Veronika Šanderová, Petr Šuleř ${ }^{1}$, and Anna Hodinová1 \\ ${ }^{1}$ Institute of Technology and Business in České Budějovice, School of Expertness and Valuation, \\ Okružní 517/10, 37001 České Budějovice, Czech Republic
}

\begin{abstract}
The topic of supply and demand for jobs is a very current and important topic, as their prediction contributes to the future operation of an organization. The base source of data is information and data obtained from online databases of the Ministry of Labor and Social Affairs of the Czech Republic. The aim of this work is to predict the supply and demand for jobs up to 2022, using the method of exponential alignment of time series. With the existence of natural unemployment, not all job positions will be filled. In such a situation, organizations will have to demand labor from abroad. In the event that organizations are unable to secure labor from abroad, they will have to reduce their activities and the associated volume of production they produce. Last but not least, the organization can start going bankrupt. In the forecast, we do not address the structure of unemployment by the highest attained education or by profession. We see the application benefits of the work in companies that manage human resources. At present, the prediction of future development is mostly at the national level and in the Czech Republic it is at the beginning of its journey. The developed methodology will enable organizations to monitor the current situation on the labor market and respond to changes in the short and long term.
\end{abstract}

Keywords: human resources, supply, demand, job position prediction JEL codes: J22, J23

\section{Introduction}

The most important area in an organization is human resources and the organization should pay more attention to them. Members of the Human Resources Management Department provide the knowledge, tools, training, administrative services, coaching, legal and management consulting, and talent management oversight that the rest of the organization needs to function successfully $[1,2]$. Over the past thirty years, a number of empirical studies have argued that the content of human resource management (HRM) has a positive effect on an organization's performance [3].

Labor demand is an important part of any organization for its future operation. According to Šikýr [4], human resource planning serves to realize the strategic goals of the organization, allows to determine the need of employees, estimate the coverage of these needs from both

*Author's contact information: machova@mail.vstecb.cz 
internal and external sources, prevents shortage or surplus of employees and also serves to meet the needs of employees and allows planning their development and career.

However, the impact of HRM content on organizational performance across different settings still remains unanswered [5]. These different settings may represent boundary conditions for the effectiveness and efficiency of human resource management content for individual and organizational performance [6].

The organization anticipates how many and which employees it will need over the course of one year or over the next few years in order to know how much work it must provide and thus achieve the expected goals. In other words, the organization estimates the demand for labor [4]. Too many studies, especially in the area of strategic human resource management, ignore the impact of context or, at best, attempt at "context control", leading to a "(mostly) closed system". The irony is that the neglect of human and social outcomes over the past thirty years has made HRM a success $[7,8,9]$.

When planning human resources, it is effective to start from the planned volume of production of the organization, on the basis of which the total need for employees is estimated and the total needs of employees are covered from internal resources [4]. Although concepts such as human resource management and engagement help us understand how employees respond to HRM, several authors still raise concerns that HRM research remains too management-focused and exclusively addresses managers' initiatives to explain employee perceptions and responses to HRM.

The point of view can also be extended to interface regarding interactions between the labor market and the state or, more precisely, the government. The labor market is highly influenced by the government, especially from the position of a major employer. The public sector, which consists of, for example, the police, the army, but also health institutions and education, offers many job positions, which are valued by set salaries [10].

Although evidence suggests that the effectiveness and efficiency of human resource management content depends on unforeseen events, such as product or industry, there are still unanswered questions about the effectiveness and efficiency of human resource management in recession situations or situations where the economy moves dynamically around its equilibrium conditions [5].

The aim of this work is to map the labor market in the Czech Republic with a focus on predicting supply and demand up to 2022 .

To achieve this goal, we set the following research questions:

RQ1: How will supply develop up until the year 2022?

RQ2: How will demand develop up until the year 2022?

\section{Literature research}

On the labor market, both supply and demand are key factors in determining the appropriate salary for both jobseekers and employers. However, it is difficult to discover supply and demand in any labor market. For each labor market, the supply and demand of the labor market is constructed using job offers and the response of candidates. Equilibrium wage and equilibrium workload are calculated on the basis of supply and demand [11]. Predicting the difference between supply and demand is a type of traffic flow prediction that aims to predict the difference between supply and demand for the next period of time when historical traffic data is given [12]. Many researchers create various algorithms to obtain information about occupations and specific skills from online job advertisement databases. These sources provide a wealth of information on the labor market. However, this data is generally unstructured. Online job vacancy databases generally have unstructured text boxes that contain information about the occupation and skills required. However, such fields are 
manually filled in by company representatives and this requires data preparation procedures and algorithmic techniques to be implemented in order to obtain relevant information in a standardized form [13]. Boon et al. [14] present an argument regarding skills that is supported by the results of Green and Henseke [15] and Harvey and Turnbull [16]. These authors emphasized the growing importance of specific skills for labor market outcomes, such as wages. Green and Henseke [15] emphasizes the fact that employees with a combination of social and mathematical skills receive higher rewards than those with other skills, but Harvey and Turnbull [16] show that workers with certain skills (i.e. higher levels of selforganization) can receive higher rewards in digitally demanding industries compared to less digitally demanding industries. However, only the study of changes in employment shares can neglect important aspects of real skills demand, as shown by Katou [17] and Green and Henseke [15]. On the one hand, the job serves as a representative for skills requirements and experience requirements at the same time. This is because employment is a balanced outcome of labor demand and supply, which is assumed to be inflexible in the short term. In addition, due to the growing technological capacity to replace human labor, it is essential to gain a better understanding of changing skills and skill combinations. Ternikov and Aleksandrova [18] point to this, increasing productivity has positive effects, thanks to automation, which under certain conditions leads to growing demand for labor, skills shortages can have significant negative effects with far-reaching consequences for inequality. Way et al. [19] stated that "improved technology and capabilities contribute indirectly to economic growth through extensive scientific and technical training and learning by practice". The first goal is to model labor markets using the theory of supply and demand. In this approach, we use job position and application data collected from large job portals.

\section{Data and methods}

\subsection{Data}

The base source of data will be data from the Ministry of Labor and Social Affairs of the Czech Republic, where we collected data on labor supply and demand from the last five years from the file Analysis of the demand for labor and supply of labor. The data was collected from December 31, 2015, to March 31, 2021. All obtained data is from the whole of the Czech Republic for a monthly period. We exported the data obtained from the Ministry of Labor and Social Affairs to Microsoft Excel, where we graphically displayed time series of supply and demand using a line graph.

The number of jobs offered has been steadily declining since January 2016 from 467,403 to 215,010 jobs in November 2018. The supply curve will rise sharply in December 2018 to 457,506 jobs. From January 31, 2019, the supply curve will be declining slightly and in December 2019 the number of jobs offered will fall to 215,532 . The supply as of January 31 , 2020 amounts to 230,022 jobs offered, and since then the supply curve has been declining slightly up until March 2020. From April 31, 2020, the number of jobs offered is growing and at the end of 2020 the number of jobs offered is 291,977 in 2021, the number of positions offered will change slightly in the first three months, but the value will not fall below 300,000 .

From December 31, 2015, the demand for jobs increased slightly from 102,564 jobs in demand to 141,024 until September 2016. From September 2016 to the end of 2016, the demand curve slightly decreased to 132,519 jobs in demand. From the beginning of 2017, the number of requested places has been constantly increasing up to November 31,2018 , to 323,570 . In December 2018, the number of demanded jobs will fall to 225,972, and then the demand will start to grow again until August 2019, when 350,556 jobs are demanded. From then on, the demand curve fluctuates slightly between 330 thousand and 341 thousand. As of 
August 31, 2020, the number of jobs in demand is 340,824 and the value decreases slightly to 310,729 in October 2020. From November 2020 to March 2021, the demand curve rises to 338,864 jobs in demand.

Chart No. 1 shows the number of jobs offered and demanded from December 31, 2015 to March 31, 2021.

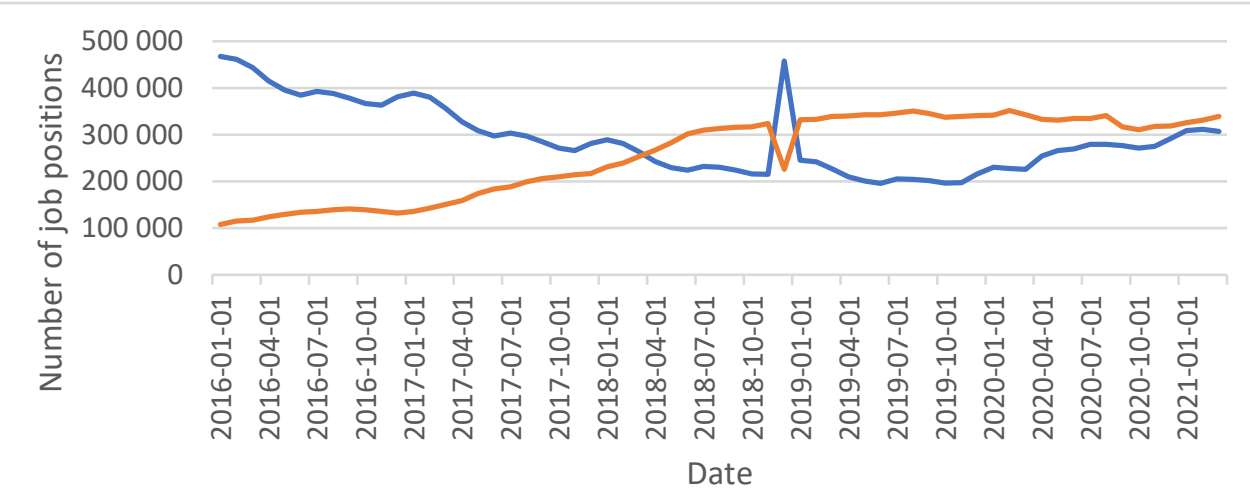

- Supply Demand

Fig. 1. Actual course of time series

Source: Authors.

The data will be provided by the internet portal https://data.mpsv.cz/web/data/analyzapoptavky-po-pracovni-sile-a-nabidky-pracovni-sily [online]. [cit. 2021-5-23].

\subsection{Methods}

To predict supply and demand, we choose the method of exponential alignment of time series. We will create a file in Microsoft Excel, where we will record the data obtained from the Ministry of Labor and Social Affairs, which will be divided into columns A, B, C and the number of rows will be 64 . The first row will contain the name of the variables Month, Supply, Demand, and the other rows will be variables. We then import the generated file from Microsoft Excel into Statistica software from Tibco in version 14.0.0.15 and click on the Statistics tab. In the Statistics tab, we select advanced models and then time predictions. We will select variable in the time prediction and we will deal with the supply first. Then we select the exponential alignment and prediction. The seasonal component will be twelve, because we will monitor the seasonality monthly. This means dividing the time series into twelve time series. The forecast of the demand is given up until the end of 2022. In 2022 it is twelve months and in 2021 we had data for the first three months. Therefore, we will predict for 21 months. We will not change the division of individual scales and leave it on the default settings. We set the maximum number of iterations to 100; in doing so we should achieve greater accuracy. We will choose a model that works with seasonal fluctuations. We use the Linear Trend and choose the Multiplicative model that works with Alpha, Delta and Gamma components. This Multiplicative model means that the trend will be linear downwards or upwards and deviations will develop from it. We will prepare a demand forecast in the same way. By this point, we will have both time series calculated.

We then insert the processed data into Microsoft Excel, where we create a line graph from the supply and demand prediction data. The next step will be residue detection. In the Excel 
file, we will create columns A, B, C named Month, Supply - Residues and Demand Residues. If we want a higher accuracy of the model, we find it using the correlation coefficient. We find the correlation coefficient from the data Supply or Demand and Smoothing of the time series.

\section{Results}

As already mentioned in the methodology, using exponential alignment of time series, we predicted the supply and demand for jobs from April 30, 2021 to December 31, 2022. The development of job supply was presented, which is shown in Figure No. 2. The graph shows that the supply curve will increase slightly from the second quarter of 2021 and this situation will persist until the end of the forecast period. Compared to 2019, the subsequent demand for value will increase relatively with smaller deviations. The prediction graph is a smoothed time series of supply and demand.

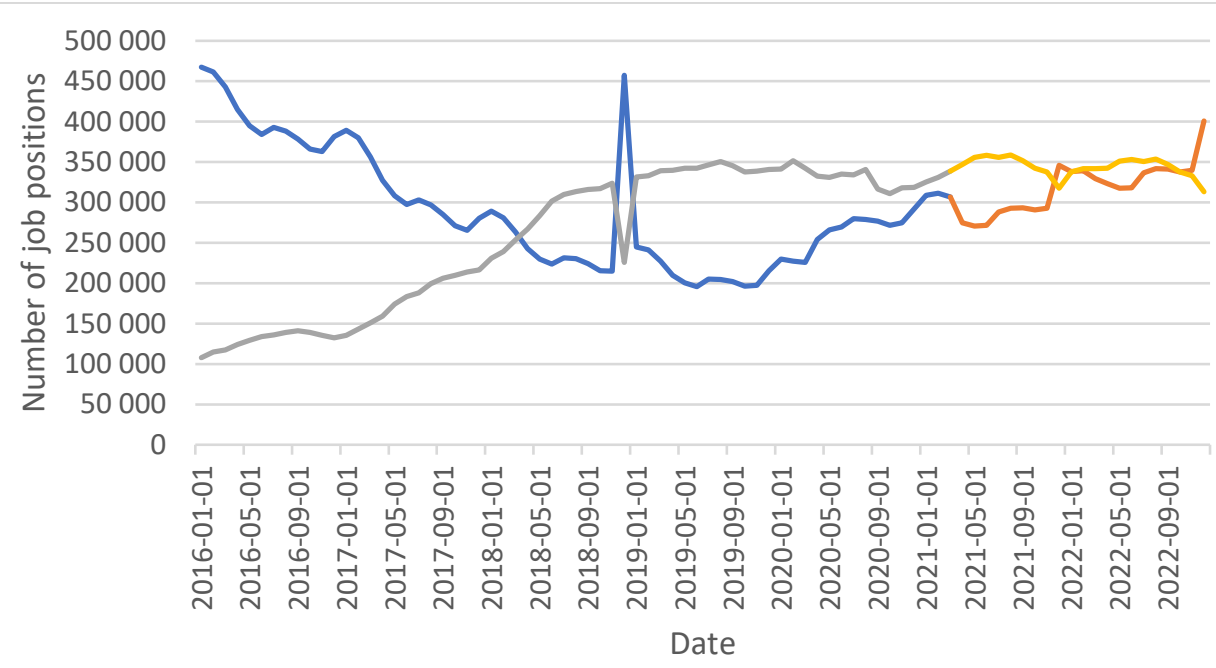

- Supply Supply-prediction —Demand - Demand-prediction

Fig. 2. Actual course of time series with subsequent prediction of supply and demand Source: Authors.

From Figure No. 2 we can read that the number of predicted offered jobs from April 30, 2021 at 274,642 will start to decrease slightly by June 2021 to 271,449 predicted offered jobs. From July 31, 2021 to November 2021, the number of predicted positions offered will not exceed 300,000 . At the end of 2021, the number of predicted jobs offered will increase to 346,130 and from then on the supply curve will begin to decline slightly to 317,984 in June 2022. The number of predicted jobs offered will increase slightly up until September 2022 and then begin to decline slightly until November 2022. At the end of the year 2022, 400,783 offered jobs are predicted.

The demand forecast curve from March 2021, when 338,864 positions in demand are registered, increases to 358,683 positions by August 31, 2021. From August 2021 to December 2021, the number of predicted positions will decrease slightly to 317,769 positions. From the beginning of 2022, the number of predicted demanded jobs will increase slightly until August 2022, when the number of demanded jobs will be 353,574. From then 
on, the number of predicted demanded jobs will decrease slightly until the end of 2022 to 313,221 predicted demanded jobs.

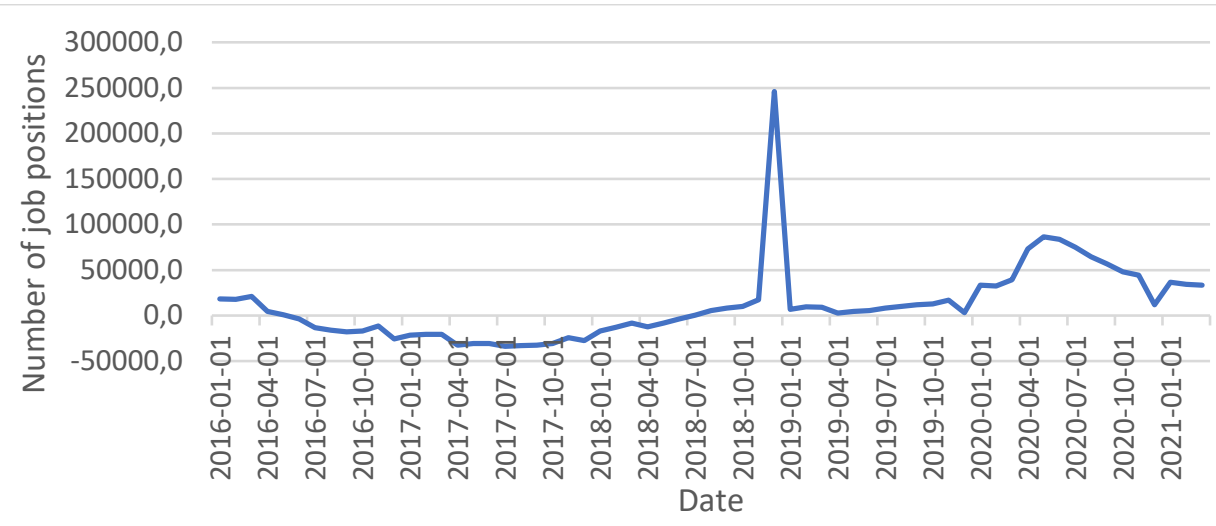

Fig. 3. Supply - residues

Source: Authors.

The chart Supply - Residues and Demand - Residues graphically shows us a line graph created in Microsoft Excel. The obtained data is the difference between the actual and predicted variables. In this case, they show us how the model differs from reality.

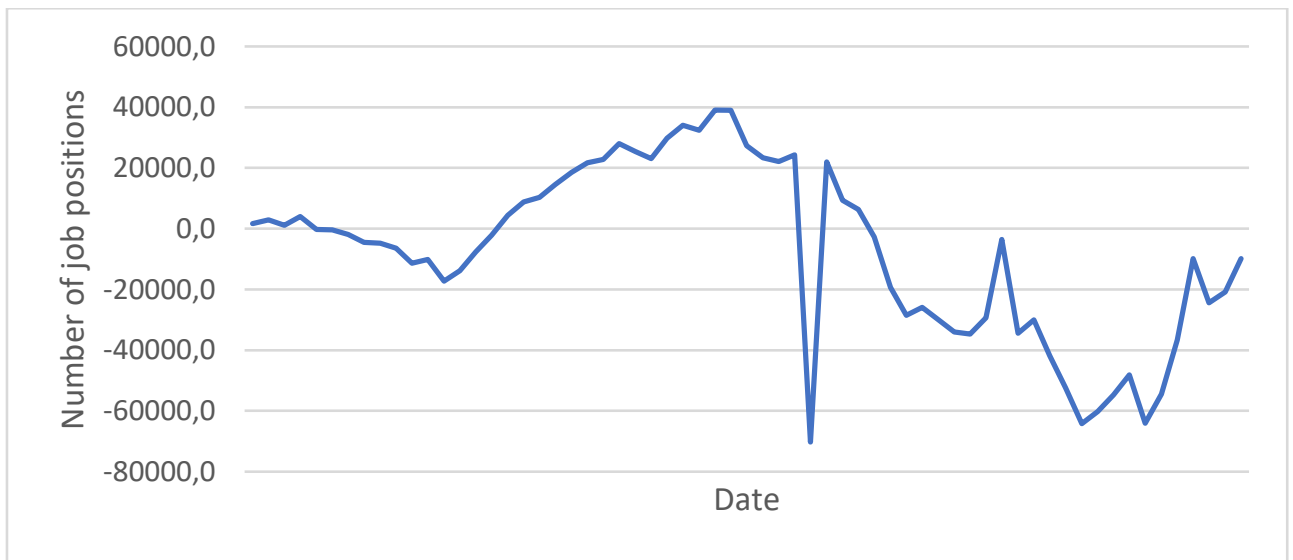

Fig. 4. Demand - residues

Source: Authors.

Figure No. 2 and 3 show sharp fluctuations in values, which were also reflected in the models. The reason for such sharp fluctuations in the supply and demand curve is the fact that the models were unable to detect them in time.

Comparing charts 2 and 3, we can see that the model is relatively accurate. By applying time series alignment, we obtained a model and then applied this model to all data. If we want a higher accuracy of the model, we find it using the correlation coefficient. The closer the correlation coefficient is to 1 , the more accurate the model will be. The supply correlation rate is relatively high at 0.86 , but the demand correlation rate of 0.96 is even higher. A statistically significant value of the correlation coefficient is 0.7 and more. As a result, this means that the result is relatively valid. 


\section{Discussion}

Based on the obtained results, we are able to answer research questions that were determined:

RQ1: How will supply develop up until the year 2022?

We predicted the supply up to 2022 with a suitable chosen method of exponential alignment of time series and displayed it using a line graph created in Microsoft Excel. We have found that the supply curve will grow from March 31, 202. The supply of job positions will be affected by the demand for jobs, which will be higher than the number of jobs offered. However, at the end of the forecast period on December 31,2022, there will be a change in which the supply curve will rise sharply. In this case, the demand curve for jobs will start to decline gradually.

\section{RQ2: How will demand develop up until the year 2022?}

In the same way as we calculated the development of supply until 2022, we also found out the development of demand until 2022. The demand for jobs will increase relatively from March 31, 2021, with small deviations. The value of demand will decline December 31, 2022 and will subsequently increase again.

In this paper, we also created two charts focusing on supply residues and demand residues. The values in these charts were from the period of December 31, 2015 to March 31, 2021 The duration of the residue is only from the beginning of the period to the end of the period when we had the data obtained from the Ministry of Labor and Social Affairs of the Czech Republic. We then compared the chart of residue supply and residue demand with the graph of actual time series. The aim of these charts was to record how the actual and predicted variables differ.

\section{Conclusion}

The aim of the paper was achieved. Through exponential alignment of time series, we predicted the supply and demand for jobs in the labor market in the Czech Republic. When creating charts, predicting supply and demand, we chose a model that works with seasonal fluctuations. The presence of a seasonal component was present in all of the time series analyzed. We chose a multiplicative model with a number of iterations of 100 to achieve greater accuracy. For higher accuracy, we also chose to calculate the correlation coefficient.

Predicting supply and demand is not easy because we do not know which direction the labor market will take. In particular, technological change cannot be determined exactly at what rate they will be used or forgotten. In such a case, organizations will have to demand labor from abroad. If organizations are unable to secure labor from abroad, they will have to reduce their activities and the associated volume of production they produce. Last but not least, the organization can start going bankrupt.

We see the application benefits of this work in companies that manage human resources. At present, the prediction of future development is mostly at the national level and in the Czech Republic it is at the beginning of its journey. Predicting future developments in the labor market is one of the most effective tools of active employment policy. Thanks to this, we can address the unemployment factor before it happens. However, the biggest advantage of prediction is the provision of timely information on changes in supply or demand for job positions. This information serves as a basis for organizations in decision-making and setting strategic goals. The strategic goals will make it possible to determine the need for employees and the volume of production that the organization will be able to implement in the coming years. In the forecast, we did not address the structure of unemployment by educational attainment or by profession. The developed methodology will enable organizations to 
monitor the current situation on the labor market and respond to changes in the short and long term. The output of the prediction was information that corresponds to the needs of the labor market in a given time interval. In this case, up to the end of 2022.

\section{References}

1. R. Maňák, Approach to human resources performance measurement. Littera Scripta, 6(1), 82-94 (2013)

2. S. M. Heathfield, What is human resource management? [online], Available at: http://humanresources.about.com/od/glossaryh/f/hr_management.htm (2021)

3. L. Dienesová, M. Šuta, Conference Review. "Entrepreneurial competences and human resource management in the $21^{\text {st }}$ century. Littera Scripta, 10(2), 180-184 (2017)

4. M. Šikýr̆, Human resources for managers and human resources. 2. Eds. Prague: Grada (2016)

5. B. Okay-Somerville, D. Scholarios, A multilevel examination of skills-oriented HRM and perceived skill utilization during recession: implications for the wellbeing of all workers. Human Resource Management, 58(2), 139-154 (2019)

6. Y. Hong, Y. Jiang, H. Liao, M. C. Sturman, High performance work systems for service quality: boundary conditions and influence processes. Human Resource Management, 56(5), 747-767 (2017)

7. C. Jane Hollowell, Z. Rowland, T. Klieštik, J. Klieštiková, V. V. Dengov, Customer loyalty in the sharing economy platforms: How digital personal reputation and feedback systems facilitate interaction and trust between strangers. Journal of Self-Governance and Management Economics, 7(1), 13-18 (2019)

8. M. J. Donate, I. Pena, J. D. S. de Pablo, HRM practices for human and social capital development: effects on innovation capabilities. International Journal of Human Resource Management, 27(9), 928-953 (2016)

9. W. Wikhamn, Innovation, sustainable HRM and customer satisfaction. International Journal of Hospitality Management, 76, 102-110 (2019) (za číslo 7)

10. H. Lipovská, Modern economics: simply about everything you should know. 1 Eds. Prague: Grada (2017)

11. H. S. Sugiarto, E. Lim, N. L. Sim, On analysing supply and demand in labor markets: Framework, model and system. IEEE International Conference on Data Science and Advanced Analytics 6th DSAA, pp. 511-520 (2019)

12. D. Wang, W. Cao, J. Li, J. Ye, DeepSD: Prediction of supply and demand for online voting services using deep neural networks. Proceedings IEEE 33. International Conference on Data Engineering. (ICDE), pp. 243-254 (2017)

13. R. Boselli, M. Cesarini., F. Mercorio, M. Mezzanzanica, Classifying online job advertisements through machine learning. Future Generation Computer Systems, 86, 319-328 (2018)

14. C. Boon, D. N. Den Hartog, A systematic review of human resource management systems and their measurement. Journal of Management, 45(6), 2498-2537 (2019)

15. F. Green, G. Henseke, Europe's evolving graduate labour markets: supply, demand, underemployment and pay. Journal for Labour Market Research, 55(2) (2021) 
16. G, Harvey, P. Turnbull, Ricardo flies Ryanair: Strategic human resource management and competitive advantage in a single European aviation market. Human Resource Management Journal, 30(4), 553-565 (2020)

17. A. A. Katou, Human resources flexibility as a mediating mechanism between high performance work systems and organizational performance: A multilevel quasilongitudinal study. EuroMed Journal of Business (2021)

18. A. A. Ternikov, E. A. Aleksandrova, Demand for skills on the labor market in the IT sector. Business Informatics, 14(2), 64-83 (2020)

19. S. A. Way, P. M. Wright, J. B. Tracey, J. F. Isnard, HR flexibility: precursors and the contingent impact on firm financial performance. Human Resource Management, 57(2), 567-582 (2018) 